\title{
AS IDENTIDADES DOS ENFERMEIROS EM CENÁRIOS DE MUDANÇAS CURRICULARES NO ENSINO DA ENFERMAGEM
}

\author{
THE IDENTITIES OF NURSES IN SCENARIOS OF CHANGES IN THE CURRICULUM OF \\ NURSING EDUCATION
}

\author{
Rogério Dias Renovato ${ }^{1}$ \\ Maria Helena Salgado Bagnato ${ }^{2}$ \\ Lourdes Missio ${ }^{3}$ \\ Greicelene Aparecida Hespanhol Bassinello ${ }^{4}$
}

Resumo As discussões sobre o currículo de enfermagem remontam o início do século $\mathrm{XX}$, trazendo tentativas de reorganizar o ensino desta área. As primeiras escolas tiveram o ambiente hospitalar e o modelo biomédico como aporte para o ensino e a assistência. Com a expansão da assistência médicohospitalar, afloraram os discursos da enfermagem como profissão comprometida com a ciência. Por muitos anos, predominou uma formação tecnicista, com aprimoramento da atenção curativa levando ao descompasso com as necessidades de saúde da população. Com o ideário da Reforma Sanitária nos anos 80 , a enfermagem procurou articular as dimensões clínicas e epidemiológicas sob a perspectiva do coletivo, culminando na adoção de novas matrizes curriculares. Em 2001, a publicação das diretrizes curriculares preconizou uma formação generalista, humanista, crítica e reflexiva. Porém, as leituras e os significados sobre as propostas das diretrizes podem sofrer interferências locais, produzindo discussões, resistências e enfrentamentos, compondo outras subjetividades acerca desse profissional. Assim, nossa proposta é articular a (re)construção das identidades dos enfermeiros contemporâneos em cenários de propostas e mudanças curriculares nos cursos de graduação em enfermagem, procurando compreender como o passado das matrizes curriculares foi/é trazido para o presente a fim de produzir outras e novas subjetividades.

Palavras-chave enfermagem; currículo; ensino da enfermagem; identidade.
Abstract Discussions about the curriculum of nursing refer back to the beginning of the twentieth century, bringing attempts to reorganize the teaching methods of this area. The first schools had a hospital environment and a biomedical model as a contribution for education and assistance. With the expansion of medical and hospital care, the concept of nursing was viewed as a profession committed to science. For many years, technical education was predominant, enhancing curative care which lead to the inconsistency of the health needs of the population. With the ideals of the Health Reform in the 80s, nursing tried to articulate the clinical and epidemiological dimensions from a collective perspective, culminating in the adoption of new curriculum matrices. In 2001, the publication of the curriculum guidelines recommended a generalist, humanist, critical, and reflective education. However, the readings and meanings of the proposed guidelines may suffer local interferences, causing discussions, resistances, and confrontations. These elements bring on other subjectivities about this professional. Thus, our proposal is to articulate the (re)construction of contemporary nurses' identities in scenarios of proposals and curricular changes in nursing graduate programs, seeking an understanding of how the past of curriculum matrices was/is brought to the present with the objective of producing other and new subjectivities.

Keywords nursing; curriculum; nursing education; identity. 


\section{Introdução}

As discussões sobre o currículo de enfermagem remontam o início do século $\mathrm{XX}$, trazendo tentativas de reorganizar o ensino desta área através da definição de disciplinas que se aproximavam das ciências biomédicas. Assim, as enfermeiras e os enfermeiros deveriam ser hábeis em se ajustar a essas mudanças, rompendo com as tradições do passado, tendo como cenário principal de atuação o ambiente hospitalar.

No final do século XIX, foi criada através do decreto n. ${ }^{\circ} 791$, de 27 de setembro de 1890, a primeira escola oficial de enfermagem no estado do Rio de Janeiro, a Escola Profissional de Enfermeiros e Enfermeiras, anexa ao Hospício Nacional. A referida escola orientava-se pelo modelo francês da Escola Salpetrière (Carvalho, 1976). Todavia, apenas em 1901, foi introduzido no Brasil o modelo nightingaleano, ainda que de forma incipiente, na Escola de Enfermeiras do Hospital Evangélico (atual Samaritano), Rio de Janeiro, paradigma de considerável influência nas práticas de enfermagem, bem como na definição das primeiras matrizes curriculares nacionais (Saupe, 1998).

Em 1923, com a chegada de um grupo de enfermeiras americanas ao país, fundou-se a escola de enfermagem ligada ao Departamento Nacional de Saúde Pública (DNSP), a Escola de Enfermagem Anna Nery, no Rio de Janeiro (Germano, 1983). Porém, para Rizzotto (1995), a criação dessa escola teve, na figura de Carlos Chagas, papel fundamental e idealista na institucionalização da enfermagem moderna brasileira.

Apesar de forte influência norte-americana, sua principal preocupação foi estender a formação dessas profissionais para o âmbito da saúde pública, tese refutada por Rizzotto (1995) que, ao analisar a matriz curricular da Escola de Enfermagem Anna Nery, verificou o enfoque centrado no espaço hospitalar e no estudo sistemático de doenças. Além disso, a fragmentação de conteúdos a partir de grande número de disciplinas trouxe prejuízos ao ensino da enfermagem, que priorizava a formação na prática cotidiana, tendo os estudos teóricos um peso menor.

Na década de 1930, o decreto n. ${ }^{\circ} 20.109 / 31$ regulamentou o exercício da profissão no Brasil e fixou condições para a equiparação das escolas de enfermagem à Escola Anna Nery, que foi estabelecida como padrão oficial para o ensino dessa área no país.

Somente em 1949, com a expansão da assistência médica-hospitalar e a reestruturação do Ensino Superior, no primeiro governo Vargas, o ensino de enfermagem passou a agregar em seu currículo novos métodos de ensino, a inserção de grande número de especialidades médicas e a aproximação incipiente com o campo das ciências sociais. Nesse período, afloraram os discursos da enfermagem como profissão comprometida com a ciência e a tecnologia. 
A partir de 1960, novas mudanças curriculares foram aplicadas, como a determinação do currículo mínimo e a criação das especializações, em 1962, enquanto as habilitações foram previstas no parecer $n .{ }^{\circ} 163$, de 1972 . Essa última modificação no currículo da enfermagem comprovou que o saber da enfermeira e do enfermeiro estava bastante delimitado pelo saber biomédico, configurando relações de poder que fortaleciam as políticas de saúde curativistas em detrimento de ações preventivas. Desse modo, o processo saúde-doença veiculado no ensino da enfermagem encontrava-se desprovido das dimensões sociais (Bagnato, 1994).

Durante as décadas seguintes, a insatisfação quanto à formação profissional teve como palco de vários debates encontros regionais e nacionais, o que culminou na adoção de uma outra matriz curricular em 1994. Todavia, em 2001, as diretrizes curriculares para os cursos de graduação em enfermagem propuseram outras concepções, atropelando um processo de mudanças que ainda estava em expansão, o que acarretou esforços e mais discussões para a implementação desse novo profissional da enfermagem.

Portanto, a proposta desse trabalho é articular a (re)construção das identidades da enfermeira e do enfermeiro contemporâneos emoldurados em cenários de propostas e mudanças curriculares nos cursos de graduação em enfermagem, procurando compreender como o passado das matrizes curriculares foi/é trazido para o presente a fim de disciplinar, regular, normatizar e produzir outras e novas subjetividades.

Pretendemos abordar com mais insistência as reformulações curriculares realizadas a partir da década de 1970, procurando tecer aproximações com o campo do trabalho em saúde. Não temos a pretensão de esgotar essa discussão, nem ignorar as tensões e lutas evidenciadas no ensino da enfermagem, a partir de uma descrição acrítica e linear de eventos históricos, mas considerar os processos de recontextualização entre o macro e micro e como isso pode contribuir na constituição de enfermeiras e enfermeiros brasileiros na contemporaneidade.

Para o caminho no qual pretendemos trilhar, utilizamos alguns pressupostos provenientes do campo do currículo. Dentre eles: os currículos foram e são resultantes da seleção de conhecimentos e saberes construídos historicamente; os currículos foram e são uma questão de identidade, pois contribuem e contribuíram na produção de subjetividades; os currículos envolvem relações de poder e podem ser formas de representação de sistemas de regulação e de controle (Silva, 2004). 


\section{As matrizes curriculares e as consequentes subjetividades da enfermeira e do enfermeiro nos primórdios da enfermagem moderna brasileira}

O ensino superior em enfermagem no Brasil tem demonstrado fortes vínculos com as transformações políticas e técnicas da área da educação e da saúde. Neste sentido, repensar a formação nesta área passou a ser uma exigência tendo em vista os desafios contemporâneos que estão inseridos no contexto das transformações econômicas, políticas, sociais e culturais.

A origem do ensino superior em enfermagem remonta o início do século XX, período marcado por grandes mudanças geradas pelo processo de urbanização e industrialização. Em decorrência desses fatores, a saúde pública enfrentava graves crises decorrentes de epidemias e endemias que representavam uma ameaça à população e à economia brasileira, havendo necessidade de melhorar as condições sanitárias, principalmente nos portos, para dar continuidade às transações comerciais (Germano, 2003).

Com o intuito de estruturar um serviço de enfermagem em saúde pública, foi organizada a Escola de Enfermeiras do Departamento Nacional de Saúde Pública, através do decreto $n .{ }^{\circ} 16.300 / 23$, que regulamentou o funcionamento e o currículo da escola. O ingresso no curso era permitido somente para mulheres e estas deveriam ter diploma de uma escola normal ou instituição secundária equivalente, apresentar atestado firmado por médico do DNSP garantindo condições de saúde física e mental, ausência de doenças contagiosas e defeitos físicos, ter de 20 a 35 anos e apresentar referências de boa conduta (Pires, 1989; Missio, 2007).

A identificação da enfermagem com o sexo feminino encontrou ressonâncias em discursos que procuraram naturalizar o papel da mulher, dentre eles, que a enfermagem pertencia ao domínio doméstico e o lar seria o recinto dominante da mulher. A enfermagem como chamado e não como trabalho teve sua imagem esculpida simbolicamente a partir da figura de Florence Nightingale, a lady com a lâmpada.

Porém, outras perspectivas podem elucidar a enfermagem como sendo essencialmente feminina, dentre elas, a necessidade de auxiliares mais aptos para ajudar o trabalho médico e a pouca ambição das mulheres, o que facilitaria o cumprimento das ordens e o respeito às hierarquias (Mott, 1999).

O curso de enfermagem do DNSP oferecido pela escola tinha duração de dois anos e quatro meses. Apesar da exigência de curso normal ou secundário para admissão na escola, permitia-se às candidatas, quando na falta de diploma neste nível, serem admitidas se provassem capacitação para o curso. Além disso, a prestação de oito horas diárias de serviço no hospital era obrigatória (Medeiros et al., 2001).

Todavia, a estrutura da saúde pública brasileira voltou-se para programas de saúde de problemas específicos, e o principal campo de atuação das 
enfermeiras formadas foi o espaço hospitalar, com exceção dos programas de combate à tuberculose, financiados pela Fundação Rockefeller. Sem contar que o modelo nightingaleano adotado pela enfermagem brasileira tinha no ambiente hospitalar seu lócus principal de formação. Rizzotto (1995) também relata que a origem social das primeiras enfermeiras, oriundas principalmente da classe média e classe alta, não favoreceu a sua permanência no trabalho de enfermeiras de saúde pública ou enfermeiras visitadoras, considerado penoso e insalubre.

Em 31 de março de 1926, por meio do decreto n. ${ }^{\circ}$ 17.268, a Escola de Enfermeiras do Departamento Nacional de Saúde Pública passou a denominar-se Escola de Enfermeiras Anna Nery (Germano, 1983). O modelo de formação adotado nesta instituição ficou conhecido como padrão Anna Nery (PAN) e perdurou até meados da metade do século passado, sendo substituído e contestado por outros modelos, dentre eles o apoiado pelo Serviço Especial de Saúde Pública, que incentivava consideravelmente o ensino da enfermagem no Brasil, principalmente a Escola de Enfermagem de São Paulo (Almeida Filho, 2004).

Conforme relatado anteriormente, esse modelo de ensino para a enfermagem implantado no Brasil promoveu a feminilização da profissão através do ingresso restrito às mulheres. $\mathrm{O}$ ingresso de homens nas escolas de enfermagem brasileiras somente foi possível a partir de 1949, rompendo a obrigatoriedade de ser mulher para ingressar na profissão em nível superior (Pereira, 2008). Contudo, até o início do século XX, a enfermagem foi uma atividade exercida por homens e mulheres, tornando-se uma profissão feminina apenas no decorrer deste mesmo século (Mott, 1999). Ou seja, o processo de feminilização foi uma escolha arbitrária e entremeada de interesses, envolvendo relações de gênero e embates identitários.

A construção do saber e do conhecimento em enfermagem, nesse período, não era centrado no cuidado ao ser humano, mas sim na execução de tarefas. Segundo Waldow (1998), as escolas de enfermagem exigiam de modo bastante rígido o desempenho de procedimentos sem, todavia, deter-se no porquê desse trabalho. A preocupação exacerbada no fazer caracterizava o processo educativo em enfermagem como uma soma de treinamento mais o aprendizado das causas das doenças, sua descrição e seu tratamento.

A partir dos anos 40, com o desenvolvimento acelerado do complexo médico-industrial e farmacêutico, o movimento de renovação dos hospitais e o surgimento de um novo mercado de trabalho, o Ensino Superior em enfermagem passou por transformações curriculares objetivando formar profissionais com maior competência técnica para o exercício profissional (Germano, 2003).

A primeira reformulação curricular foi em 1949 (decreto n. ${ }^{\circ} 27.426$, de novembro de 1949), alterando principalmente o nível de escolaridade dos 
candidatos para o ingresso no curso, passando a exigir como requisito inicial o curso ginasial ou equivalente. Foram incluídas no currículo as disciplinas de Sociologia e Psicologia e o aumento da duração do curso para 36 meses (Bagnato, 1994). Porém, conforme relatam Galleguillos e Oliveira (2001), essas mudanças curriculares seguiram o modelo norte-americano, permeado de especialidades médicas, sem, no entanto, dispor dos mesmos aparatos tecnológicos da realidade estadunidense.

A segunda reformulação curricular no ensino superior em enfermagem ocorreu em 1962, por meio do parecer n. ${ }^{\circ} 271 / 62$, que definiu e estruturou os cursos em dois segmentos: o curso geral e as especializações em enfermagem em saúde pública e enfermagem obstétrica. A carga horária teórica foi ampliada, mas as aulas práticas foram reduzidas para atender ao movimento de intelectualização da profissão (Mendes, 1996).

Esta proposta curricular privilegiou a área curativa visando a formar profissionais para atuar em clínicas especializadas e hospitais, tornando facultativas as disciplinas voltadas para a saúde pública e reforçando o modelo pedagógico das clínicas especializadas. Também procurou uniformizar o ensino de enfermagem, estabelecendo um currículo mínimo obrigatório que serviu de orientação para as demais escolas organizarem seus cursos.

A articulação da enfermagem com os princípios científicos se fortaleceu nesse período, procurando fundamentar suas práticas e seus procedimentos técnicos aos saberes biomédicos. A enfermagem, como ciência, passou a construir outras interlocuções e, assim, delimitar seu campo de saber, procurando definir um corpo de conhecimentos específicos e de reconhecimento. O processo educativo nas universidades refletiu essa colcha de retalhos, ora uma estrutura similar ao da medicina, ora com tentativas de definir territórios de saber profissional singular e específico. Conforme relata Lopes (1998, p. 45), “as enfermeiras percebem hoje que imitar a prática médica e assimilar seus ditames técnicos representou mais responsabilidades, mas não alterou seu prestígio".

Com a inserção mais acentuada da enfermeira e do enfermeiro no campo hospitalar, os cursos de enfermagem voltaram-se para formar profissionais com ênfase no desempenho de atividades administrativas e de ensino, tendo como objetivo a supervisão da assistência de enfermagem e não mais o cuidado direto ao indivíduo, que passou a ser relegado ao atendente e aos auxiliares de enfermagem (Bagnato, 1994).

Esta mesma autora destacou que

a formação dos profissionais de saúde, historicamente, desenvolveu-se numa relação muito estreita com as políticas de saúde e econômica implementadas pelo Estado, acentuando uma formação voltada para a área hospitalar, diluindo os aspectos sociais e políticos das questões gerais de saúde predominantes na 
população, desfocando, em consequência, discussões sobre as formas de organização, prestação e distribuição dos serviços (Bagnato, 1999, p. 15).

No fim da década de 1960, a universidade brasileira passou por grandes transformações em consequência da Reforma Universitária de 1968, adequando-se ao modelo norte-americano. Com esta mudança, ocorreu a reorganização na estrutura interna, surgindo a 'departamentalização', a matrícula e a contagem de créditos por disciplinas, a implantação do ciclo básico e a institucionalização da pós-graduação. Além disso, a universidade passou a ter como princípio a indissociabilidade entre o ensino, a pesquisa e a extensão (Panache, 2003).

Neste mesmo período, observou-se um acentuado processo de privatização e especialização dos serviços de saúde, em decorrência da monopolização da economia, repercutindo diretamente nas práticas de saúde e no exercício da medicina e da enfermagem.

Bonamino, Mata e Dauster (1993) relataram que a mais estreita relação entre trabalho e educação experimentada no sistema educacional brasileiro deu-se a partir da política instituída neste período, na qual adotou-se um modelo de desenvolvimento baseado na associação com o capital internacional. Difundiu-se no país a necessidade de vincular a educação aos planejamentos econômicos globais, como forma de contribuir para o seu desenvolvimento econômico, buscando uma adequação do ensino à demanda de mão-de-obra pelo mercado de trabalho.

Com este contexto, o currículo de enfermagem foi modificado em 1972 por intermédio do parecer $n .^{\circ}$ 163/72 e da resolução n. ${ }^{\circ}$ 4/72, ambos do Conselho Federal de Educação (CFE). Com esta proposta curricular, o currículo mínimo passou a ser estruturado em dois troncos: pré-profissional e profissional comum, acrescido da opção para habilitação nas áreas de enfermagem médico-cirúrgica, enfermagem obstétrica e enfermagem em saúde pública (Mendes, 1996, Saupe, 1998).

Esta mudança aprimorou a atenção curativa em detrimento de uma preocupação com os problemas básicos de saúde e, consequentemente, o ensino de enfermagem concentrou sua atenção "nas clínicas especializadas, com vistas a dominar, cada vez mais, as técnicas avançadas em saúde, em razão da evolução científica" (Germano, 2003, p. 16).

Na vigência deste currículo, foram criadas a licenciatura em enfermagem e a organização de cursos de pós-graduação nesta área. A licenciatura visava à formação pedagógica para os professores que atuariam em cursos profissionalizantes em enfermagem. Com a pós-graduação, introduziu-se o desenvolvimento de pesquisas, produções técnico-científicas e publicações (Bagnato, 1994).

Assim, a partir da reformulação curricular de 1972 que se estendeu até o início da década de 1990, o que esperar dessa enfermeira e desse enfermeiro formados sob essa estrutura curricular? 


\section{Enfermeiras e enfermeiros tecnicistas ou tecnólogos do cuidar?}

Segundo Angerami e Correia (1996), a formação do enfermeiro e da enfermeira caracterizava-se pela sua fragmentação, que privilegiava o modelo biomédico com ênfase na técnica, sob forte influência funcionalista e centrado na perspectiva da cura do indivíduo.

À enfermeira e ao enfermeiro formados no currículo de 1972 eram transmitidos os saberes cunhados na racionalidade moderna, permeado de verdades absolutas, com a padronização do conhecimento construída sob o paradigma do positivismo. Na própria formação, percebemos a dicotomia em toda estrutura curricular: saúde/doença, ciências básicas/ciências da enfermagem, cura/prevenção. A ênfase na formação de especialistas favoreceu o saber em gavetas, que obstruíam o trabalho interdisciplinar e o apagamento das questões coletivas.

Segundo Bagnato (1994), as enfermeiras e os enfermeiros atuavam principalmente nos hospitais, exercendo funções de gerenciamento e treinamento da equipe de auxiliares. As suas ações encontravam um lócus de divisão de trabalho, sob forte hierarquização, preconizando o modus operandi do setor privado. Assim, foi possível verificar que a formação na enfermagem encontrava ressonância nesse campo de trabalho, que por sua vez influenciava sua formação tecnicista.

Dessa maneira, a enfermeira e o enfermeiro afastaram-se paulatinamente do cuidado direto, ocorrendo de modo singular e diferencial, e notoriamente contraditório. Se, por um lado, a formação universitária e o status conferido trouxeram uma certa satisfação à enfermagem, restringindo-se tão somente às atividades administrativas e atuando apenas em atividades de cuidar que requeriam mais qualificação, por outro lado o trabalho em saúde realizado pela enfermagem, em vários momentos, atendeu aos interesses das instituições hospitalares, como resultantes da falta de poder e de uma política de atuação. Os conflitos vivenciados na prática refletiram ainda a ausência de autonomia, visto que o cabedal de conhecimento formal adquirido não se fez acompanhar de avanços no domínio da assistência em saúde.

Para Silva et al. (2002), a pedagogia tecnicista no currículo de enfermagem atingiu seu ápice na mudança realizada em 1972, que ressaltava a necessidade de esse profissional ter sob seu domínio as técnicas avançadas em saúde e fundamentadas no saber biomédico. Através do tecnicismo, outras abordagens adentraram o processo educativo, porém entremeado de uma organização universitária mais burocrática, mas ainda presa aos rigores disciplinares, ao conservadorismo e ao autoritarismo dessa época.

Quais subjetividades foram então construídas e reconstruídas a partir dessa matriz curricular? A opção pedagógica que se caracterizou como tecnicista considerava como elemento nuclear o aprender a fazer. Com isso, a 
enfermeira e o enfermeiro foram instados a ser objetivos, eficientes, altamente técnicos e produtivos. O processo educativo na pedagogia tecnicista priorizava a organização racional dos meios, a instrução programada, o enfoque sistêmico e a especialização das funções (Antunes, Shigueno e Meneghin, 1999).

Sob essa perspectiva, as subjetividades foram deslocadas para uma formação individualista e individualizante, com pouca ênfase no saber coletivo e dependente das tecnologias, visto que a pedagogia tecnicista tinha como objetivo reduzir as interferências subjetivas e mecanizar o processo. Segundo Saviani (2007), essa concepção procurou transpor para o trabalho pedagógico o trabalho fabril, perdendo de vista a especificidade da educação e as complexas mediações envolvidas.

Todavia, essa formação fundamentada na neutralidade da ciência trouxe descontentamentos e contribuiu para a precarização do trabalho em enfermagem, que se refletem até os dias atuais. A necessidade de mudanças curriculares coligia com as expectativas das enfermeiras e dos enfermeiros que desejavam melhor remuneração, maior valorização pela sociedade e modificação do perfil profissional (Cocco, 1991).

\section{Intermezzo: a implantação do currículo de 1994 e a ambivalência dessa proposta}

Durante os anos 70 e início da década de 1980, emergiram no Brasil movimentos nas áreas sociais e da saúde que passaram a discutir e encaminhar propostas em direção à Reforma Sanitária brasileira. As instituições de Ensino Superior incorporaram-se nestes movimentos pela necessidade de repensar o seu papel, as reformas curriculares e as iniciativas na pesquisa e extensão de serviços da universidade na comunidade. Nas associações de classe, e principalmente na de enfermagem, discutia-se a regulamentação da profissão e o processo de formação aspirando modificações no currículo mínimo das escolas com o objetivo de formar um profissional com um novo perfil, denominado generalista. Almejava-se uma formação que valorizasse não apenas a dimensão técnica, mas o social, reconhecendo a importância do trabalho em equipe e do atendimento de demandas da comunidade. Estes fatores provocaram reflexões e revisões nos currículos dos cursos de enfermagem, materializando-se em nova reforma curricular em 1994 (Missio, 2007).

As críticas levantadas ao currículo de 1972 convergiram a partir da aproximação das pesquisas em enfermagem com outros aportes teóricos, dentre eles o materialismo histórico. Para Cocco (1991), foi fundamental a pesquisa de Raimunda Medeiros Germano, cujo novo enfoque metodológico 
procurou articular o processo educativo e a enfermagem a partir de categorias analíticas, como a hegemonia. Nesse período, as discussões contrárias à especialização precoce encontravam respaldo no marco conceitual da formação generalista, preconizando, desde já, o trabalho em comunidade através de uma prática reflexiva permanente.

Assim, as críticas ao modelo de formação linear e ao ensino pulverizado foram atravessadas pelo fervilhar de ideias sobre a construção de currículo que considerasse o processo plural, interdisciplinar, intercultural e disposto a confrontar as necessidades da comunidade. Segundo Rodrigues (2005, p. 100), "a reformulação curricular de 1994 foi fruto de uma profunda insatisfação com a formação e, além disso, das possibilidades de discussões efetivamente colocadas no cenário da saúde de uma forma geral".

Com a portaria.$^{\circ} 1.721$, de 15 de dezembro de 1994, determinando reformulação do currículo para a enfermagem, os cursos deveriam adequar-se em áreas temáticas como: Bases Biológicas e Sociais da Enfermagem, incluindo Ciências Biológicas e Ciências Humanas; Fundamentos da Enfermagem; Assistências de Enfermagem e Administração em Enfermagem. Também deveria ocorrer o aumento da carga horária mínima de 3.500 horas, com duração de quatro a seis anos letivos. Houve, ainda, distribuição das matérias/disciplinas e um percentual de carga horária para cada área temática (Missio, 2007).

Desse modo, a enfermeira e o enfermeiro provenientes das mudanças curriculares de 1994 passaram a incorporar o ideário da Reforma Sanitária, procurando articular as dimensões clínicas e epidemiológicas, sob a perspectiva do coletivo e do particular também. Porém, o processo de globalização avançava desencadeando transformações nos processos de trabalho, bem como a emergência de outras concepções curriculares, como é o caso da flexibilidade. Nesse período, ficou perceptível a ambivalência dessa matriz curricular, que ora se permeava de conteúdos provenientes da Reforma Sanitária, ora percebia-se a manutenção prioritária da assistência curativa e individual na formação de enfermeiras e enfermeiros.

Esse período de transição e implantação de nova matriz curricular coincidiu com a implementação do Sistema Único de Saúde (SUS), conforme a afirmação de Rodrigues (2005):

este novo profissional não poderia mais ser formado apenas com os fundamentos do modelo biomédico, mas voltar-se também para as ações de saúde pública (...). Mesmo a formação clínica, que deveria com certeza continuar compondo os currículos, deveria se dar em outros moldes, uma vez que os princípios do Sistema Único de Saúde, como a integralidade da assistência, poderiam perpassar tanto os espaços em que aconteciam as ações de saúde preventiva quanto aqueles em que aconteciam as ações de saúde curativa, dado que seriam elementos diversos de um único e integrado sistema de saúde (Rodrigues, 2005, p. 104). 
Entretanto, a proposta curricular implantada em 1994 não conseguiu combater as distorções que permearam o ensino na área e a enfermagem continuou a discutir os rumos do seu ensino, tendo em vista que estava sendo construída uma nova Lei de Diretrizes e Bases da Educação Nacional (LDB), aprovada em 1996 (lei n. ${ }^{\circ}$ 9.394/96). Desta forma, novos desafios foram lançados à educação nacional e ao ensino de enfermagem, abolindose os currículos mínimos dos cursos e estabelecendo as diretrizes curriculares para estruturar e reger o Ensino Superior.

Para Bassinello (2007), aspectos importantes a serem considerados neste período foram: a mudança no modelo econômico, a utilização de preceitos neoliberais e, consequentemente, a alteração do foco de atuação em educação e saúde. A autora menciona que:

ademais, considerando-se as bases técnicas do trabalho, podemos identificar que para cada organização do trabalho correspondem projetos de escolarização e propostas no campo da educação que evidenciamos no trabalho pedagógico, na formação de professores, na produção de conhecimento e nas políticas públicas. Portanto, na década de 90, já se anunciava, com as transformações ocorridas no mundo do trabalho, uma nova questão da formação profissional. De um modo geral, pode-se dizer que o ensino de enfermagem, ao nosso ver, vem aderindo a essas transformações (Bassinello, 2007, p. 181).

Contudo podemos verificar algumas positividades nesse processo de mudanças envolvendo o ensino superior em enfermagem, como a possibilidade de construção de currículos mais abertos e, em alguns casos, até currículos integrados contrapondo-se, pelo menos parcialmente à compartimentalização e à minimização do conhecimento. Outro fato a ser relatado seria a incorporação da pesquisa como importante eixo norteador na formação desses profissionais e também a intencionalidade de formar enfermeiras e enfermeiros em consonância com o SUS, "sistema de saúde a ser construído com o reconhecimento da importância do enfermeiro neste processo" (Rodrigues, 2005, p. 110).

\section{As diretrizes curriculares e as novas, outras e antigas identidades da enfermeira e do enfermeiro}

Na área da enfermagem, por um período de aproximadamente três anos, foram realizados fóruns e seminários regionais e nacionais para discutir as diretrizes norteadoras do processo de formação. Em novembro de 2001, foram homologadas as novas diretrizes curriculares para a enfermagem (resolução CNE n. ${ }^{\circ}$ 03/2001), tendo como perfil da(o) enfermeira(o) formada(o) um 
Enfermeiro, com formação generalista, humanista, crítica e reflexiva. Profissional qualificado para o exercício de enfermagem, com base no rigor científico e intelectual e pautado em princípios éticos. Capaz de conhecer e intervir sobre os problemas/situações de saúde-doença mais prevalentes no perfil epidemiológico nacional, com ênfase na sua região de atuação, identificando as dimensões bio-psico-sociais dos seus determinantes. Capacitado a atuar, com senso de responsabilidade social e compromisso com a cidadania, como promotor da saúde integral do ser humano (Brasil, 2001, p. 1).

Além disso, a resolução CNE/CES n. ${ }^{\circ} 3$, de 7 de novembro de 2001, que instituiu as Diretrizes Curriculares Nacionais do Curso de Graduação em Enfermagem, permitiu ao enfermeiro e à enfermeira duas possibilidades de formação profissional: uma generalista, humanista, crítica e reflexiva e o licenciado em enfermagem capacitado para atuar na educação básica e na educação profissional de enfermagem (Brasil, 2001).

Com a publicação das Diretrizes Curriculares Nacionais para os Cursos de Graduação em Enfermagem, em 2001, algumas concepções sobre o profissional da enfermagem, já salientadas anteriormente, se consolidaram, enquanto outras foram apresentadas. Como deveria, então, ser esse profissional?

Para Rodrigues (2005), esse perfil descrito nas diretrizes foi proveniente de discussões desde a década de 1980, que tinham como finalidade contrapor-se à especialização na formação inicial, integrar os saberes teóricos com as práticas sociais e problematizar a realidade em suas contingências. Todavia, o que se percebe na contemporaneidade são as possibilidades de múltiplas leituras que cada instituição de Ensino Superior ou cada docente ou cada discente tem sobre as concepções dessa formação generalista, crítica e reflexiva relatada nas diretrizes.

Essa polissemia de significados e sentidos já evidenciada em estudos sobre a implantação das diretrizes nos cursos de graduação em enfermagem (Lopes Neto et al., 2007; Backes, Silva e Rodrigues, 2007) reforça uma certa preocupação, como a adesão a conceitos e concepções sem um adequado aprofundamento, produzindo confusões teóricas e o descompasso entre o currículo oficial e o que é ministrado no cotidiano dos cursos.

No estudo realizado por Lopes Neto et al. (2007), constatou-se que após cinco anos de vigência das diretrizes curriculares apenas $75 \%$ dos cursos promoveram adequações em seus projetos pedagógicos. Sem dúvida, esse processo de mudanças curriculares ainda está em movimento e a fluidez e heterogeneidade da sua implantação nos mostra que as subjetividades da enfermeira e do enfermeiro decorrentes dessas transformações poderão compor variadas matrizes identitárias.

Se no currículo de 1972 a pedagogia tecnicista atingiu seu apogeu, já nas propostas descritas nas diretrizes atuais a formação em enfermagem 
encontra-se alinhada com a pedagogia crítica, em que seus atores devem promover e transformar a realidade natural e social a partir de um certo grau de conhecimento loco-regional. A pesquisa de Backes, Silva e Rodrigues (2007) reafirma esse encontro da educação em enfermagem com os teóricos críticos, principalmente Paulo Freire e a metodologia da problematização, e também com Saviani e Libâneo, autores inspirados na concepção históricocrítica. Contudo, sem discussões aprofundadas sobre as novas construções curriculares, corre-se o risco de imprecisões teóricas inquietantes e de dificuldades em transpor as concepções propostas nas diretrizes para os cenários de ensino.

Nesse movimento de subjetividades, encontram-se dois atores envolvidos: o docente e o discente. Desse modo, a formação do enfermeiro congrega mais complexidade quando consideramos a interação entre esse dois agentes do processo educativo, visto que o corpo docente é compreendido, na sua maioria, por profissionais formados em matrizes curriculares que precederam as diretrizes atuais. Assim, como foi percebido na pesquisa de Silva e Rodrigues (2008), as vozes dos docentes espelham esses momentos de transição, materializada na pouca adesão dos professores e em representações sobre o projeto político pedagógico como apenas um documento teórico, sem a possibilidade de modificar as dicotomias e as especialidades. Porém, esses docentes consideram relevantes as discussões coletivas sobre o currículo, o emprego de estratégias envolvendo seminários, oficinas e cursos de capacitação pedagógica e o necessário comprometimento para a concretização dessa construção coletiva, neste caso, a reformulação curricular.

Qual, então, seria a visão dos discentes sobre esse processo de mudanças curriculares? Para Silva e Rodrigues (2008), o diagnóstico realizado pelos alunos elucida pontos de avanço, como a incorporação de conceitos provenientes da pedagogia crítica, dentre eles, a autonomia, a emancipação e a problematização da realidade, mas ainda se percebe um processo lento de articulação entre as várias áreas do saber da enfermagem.

De modo contraditório, as Diretrizes Curriculares Nacionais para o Ensino de Enfermagem pareceram inserir o modelo de competências, que pode ter aproximações epistemológicas com as perspectivas neoliberais. Esse modelo citado anteriormente não apresenta qualquer novidade, porém encontra outros espaços e possibilidades no capitalismo tardio, podendo ser perigosa sua transposição acrítica para o campo da educação da enfermagem.

O que se espera do modelo de competências é a possibilidade de ressignificar essa concepção, além da dimensão técnico-instrumental, e assim incorporar outras dimensões, dentre elas as dimensões ética, política e estética. Nesse sentido, a ampliação deste conceito de formação para a identidade profissional principalmente na área de enfermagem, representada anteriormente apenas pela perspectiva da técnica, implica pensar novos 
modelos de formação, dentre eles os princípios do SUS e sua articulação com os desafios apresentados pela globalização e o avanço do neoliberalismo.

No entanto, Rodrigues (2005) aponta algumas críticas em relação às competências ou à pedagogia das competências. Segundo essa autora, a pedagogia das competências constituiu-se no princípio organizador de currículos, procurando uniformizar atitudes e práticas dos trabalhadores em saúde. Apesar da falta de consenso sobre a concepção de competência, o referencial de Perrenoud tem sido o mais citado e adotado. Contudo, a que preocupa em maior escala seria a aproximação da pedagogia de competências com o projeto neoliberal, favorecendo ainda mais o processo de individualização da sociedade, desprestigiando o trabalho coletivo.

A pedagogia das competências pode contribuir e acelerar algumas concepções da Teoria do Capital Humano, em que o educando seria o único capaz de promover mudanças. Com isso, as dimensões coletivas se esfumaçariam, transferindo tão somente a esse indivíduo a responsabilidade pelo seu sucesso e fracasso, como afirma Saviani (2007, p. 428), “agora é o indivíduo que terá de exercer sua capacidade de escolha visando a adquirir os meios que lhe permitam ser competitivo no mercado de trabalho". Portanto, o papel das escolas e universidades sob essa articulação entre pedagogia de competências e neoliberalismo seria apenas o de garantir o status da empregabilidade, cabendo ao indivíduo capacitar-se continuamente para adquirir novas competências e novos saberes, ao que Saviani denominou de 'a gestão do imprevisível'.

E assim perguntamos: quais os deslocamentos de subjetividades das enfermeiras e dos enfermeiros a partir da adequação dos cursos de graduação às diretrizes curriculares? Algumas pistas foram apontadas, como a busca por uma formação mais geral em detrimento das especialidades e a necessidade de problematizar a realidade e romper com a dicotomia teoria-prática. Porém, existem alguns perigos, como reforçar o processo de individualização e o risco de uma formação superficial e aligeirada.

\section{Considerações finais}

Nesta reflexão sobre as mudanças curriculares no ensino da enfermagem desde sua institucionalização até os dias atuais com a implantação das diretrizes curriculares, observamos que a formação da enfermeira e do enfermeiro esteve, por um lado, comprometida ou preocupada com o mundo do trabalho. E, por outro lado, essa imagem da enfermagem brasileira encontrou repouso na perspectiva racional biomédica.

Assim, concordamos com Nietsche (1998), que identificou três tendências no ensino da enfermagem, sem, no entanto, desconsiderar as particu- 
laridades de cada instituição de Ensino Superior e suas heterogeneidades. São elas: a pedagogia da escola tradicional, a tecnicista e a pedagogia da Escola Crítica. Esta mesma autora nos mostrou que não foi possível identificar, no ensino da enfermagem, a pedagogia da escola nova, mas forte influência dos modelos citados anteriormente e o início lento e gradual dos princípios da Escola Crítica.

Verificamos que desde o início da institucionalização do ensino da enfermagem deu-se a ênfase crescente do saber proveniente da Fisiologia, Anatomia, Imunologia, Microbiologia e outras disciplinas afins. Desse modo, a preocupação em formar assistentes para o trabalho médico em hospitais caracterizou-se por matrizes curriculares fragmentadas, desfavorecendo os conteúdos teóricos em prol da aprendizagem no campo hospitalar.

Nesse intervalo temporal, o modelo trazido pela enfermagem norteamericana e sob influência de Florence Nightingale contribuiu com a ação das enfermeiras nos hospitais, em detrimento da sua ação no campo da saúde pública. A tese histórica do entrelaçamento entre a constituição do ensino da enfermagem e a necessidade urgente de formar profissionais para atuar na saúde pública pareceu apresentar argumentos frágeis.

Assim, as reformulações curriculares nesses primórdios até a metade do século XX contribuíram para a constituição de identidades atreladas ao gênero feminino, ao respeito às hierarquias, à rigidez disciplinar e à realização de tarefas, entremeadas de saberes que passaram a definir um campo em formação, as ciências da enfermagem.

Da década de 1960 até o final do século XX, as matrizes curriculares no ensino da enfermagem contribuíram para uma formação tecnicista, permeada de discursos acerca da neutralidade científica. As enfermeiras, e agora também os poucos enfermeiros, passaram a assumir cargos de gerência nas unidades hospitalares, enquanto o campo da saúde pública teve seu espaço bastante diminuído.

Um grande avanço para o ensino da enfermagem foi sinalizado a partir do currículo de 1994, construído coletivamente pela enfermagem através da Associação Brasileira de Enfermagem, das escolas de enfermagem e da Comissão de Especialistas na Secretaria do Ensino Superior, no qual previase a necessidade de uma formação que valorizasse não apenas a dimensão técnica, mas o social, reconhecendo a importância do trabalho em equipe e do atendimento às demandas da comunidade. Essa proposta curricular, embora ambivalente, buscava a formação de um profissional mais crítico, inserido num processo histórico-social capaz de auxiliar as transformações das condições precárias de saúde da população (Missio, 2007).

No início dessa década, as diretrizes curriculares surgiram com o intuito de integrar a atenção entre ensino, serviço e gestão do sistema de saúde, objetivando contribuir tanto com a formação da identidade da enfermeira e 
do enfermeiro quanto com a construção do SUS, porém esse processo de transformação ainda se encontra em transição, vinculado às leituras locais e particulares, considerando as heterogeneidades e descontinuidades desses movimentos, que envolvem disputas, negociações, controle, regulação e relações de reciprocidade.

\section{Notas}

1 Professor adjunto da Universidade Estadual de Mato Grosso do Sul (Uems), Dourados, Mato Grosso do Sul, Brasil. Doutor em Educação pela Universidade Estadual de Campinas (Unicamp). <rrenovato@uol.com.br>

Correspondência: Rua Hilda Bergo Duarte, 296, Dourados, Mato Grosso do Sul, Brasil, CEP 79806-020.

2 Professora-doutora da Universidade Estadual de Campinas (Unicamp) e coordenadora do Laboratório de Estudos e Pesquisas em Práticas de Educação e Saúde da Faculdade de Educação da Universidade Estadual de Campinas (Praesa/FE/Unicamp). Doutora em Educação pela Universidade Estadual de Campinas (Unicamp). <mbagnato@unicamp.br>

3 Professora adjunta da Universidade Estadual de Mato Grosso do Sul (Uems). Doutora em Educação pela Universidade Estadual de Campinas (Unicamp). <lourdesmissio@uems.br>

4 Professora das Faculdades Integradas Einstein de Limeira (Fiel) e pesquisadora do Laboratório de Estudos e Pesquisas em Práticas de Educação e Saúde da Faculdade de Educação da Universidade Estadual de Campinas (Praesa/FE/Unicamp). Doutora em Educação pela Universidade Estadual de Campinas (Unicamp). <jlabas@terra.com.br>

\section{Referências}

ALMEIDA FILHO, Antonio José de. A Escola Anna Nery (EAN) no 'front' do campo de educação em enfermagem e o (re)alinhamento de posições de poder (1931-1949). Tese de Doutorado, Rio de Janeiro: Escola Anna Nery, Universidade Federal do Rio de Janeiro, 2004.

ANGERAMI, Emília Luigia Saporiti; CORREIA, Francisco de Assis. A modernidade na formação do enfermeiro: aspectos acadêmicos. In: ENCONTRO NACIONAL DE ESCOLAS DE ENFERMAGEM, 1996, São Paulo. Anais... São Paulo: Unifesp, 1996.
ANTUNES, Maria José Moraes; SHIGUENO, Luiza y Okudaira; MENEGHIN, Paolo. Métodos pedagógicos que influenciaram o planejamento das ações educativas dos enfermeiros: revisão bibliográfica. Revista da Escola de Enfermagem da USP, v. 33, n. 2, p. 165-174, 1999.

BACKES, Andressa; SILVA, Rosiele Pinho Gonzaga da; RODRIGUES, Rosa Maria. Reformas curriculares no ensino de graduação em enfermagem: processos, tendências e desafios. Ciência, Cuidado e Saúde, v. 6, p. 223-230, 2007. 
BAGNATO, Maria Helena Salgado. Licenciatura em enfermagem: para quê? Tese de Doutorado, Campinas: Faculdade de Educação, Unicamp, 1994.

Fazendo uma travessia: em pauta a formação dos profissionais da área de saúde. In: BAGNATO, Maria Helena Salgado; COCCO, Maria Inês Monteiro; DE SORDI, Mara Regina Lemes. Educação, saúde e trabalho: antigos problemas, novos contextos, outros olhares. Campinas: Alínea, 1999.

BASSINELLO, Greicelene Aparecida Hespanhol. Projeto Larga Escala: análise histórica e compreensão dos resultados para a enfermagem no estado de São Paulo. Tese de Doutorado, Campinas: Faculdade de Educação, Unicamp, 2007.

BONAMINO, Alícia; MATA, Maria L.; DAUSTER, Tânia. Educação e trabalho: uma revisão da literatura brasileira das últimas duas décadas. Cadernos de Pesquisa, n. 84, p. 50-62, 1993.

BRASIL. Conselho Nacional de Educação. Câmara de Educação Superior. Resolução CNE/CES n. ${ }^{\circ}$ 3, de 7 nov. 2001. Institui Diretrizes Curriculares Nacionais do Curso de Graduação em Enfermagem. Diário Oficial da União, seção 1, p. 37, 9 nov. 2001. Disponível em: <www.mec.gov.br >. Acesso em: 15 mar. 2005.

CARVAlHO, Anayde Corrêa de. Associação Brasileira de Enfermagem (1926-1976). Documentário. Brasília: Associação Brasileira de Enfermagem, 1976.

COCCO, Maria Inês Monteiro. A ideologia do enfermeiro: prática educativa em saúde coletiva. Dissertação de Mestrado, Campinas: Faculdade de Educação, Unicamp, 1991.

GALLEGUILLOS, Tatiana Gabriela Brassea; OLIVEIRA, Maria Amélia de Campos. A gênese e o desenvolvimento histórico do ensino de enfermagem no Brasil. Revista da Escola de Enfermagem da USP, v. 35, n. 1, p. 80-87, 2001.
GERMANO, Raimunda Medeiros. Educação e ideologia da enfermagem no Brasil. São Paulo: Cortez, 1983.

Percurso revisitado: o ensino de enfermagem no Brasil. Pro-Posições, v. 14, n. 1, p. 13-28, jan.-abr. 2003.

LOPES NETO, David et al. Aderência dos cursos de graduação em enfermagem às Diretrizes Curriculares Nacionais. Revista Brasileira de Enfermagem, v. 60, n. 6, p. 627634, 2007.

LOPES, Marta Júlia Marques. Imagem e singularidade: reinventando o saber de enfermagem. In: MEYER, Dagmar Estermann; WALDOW, Vera Regina; LOPES, Marta Júlia Marques (Orgs.). Marcas da diferença: saberes e fazeres da enfermagem contemporânea. Porto Alegre: Artes Médica, 1998.

MEDEIROS, Marcelo; TIPPLE, Anaclara Ferreira Veiga; MUNARI, Denize Bouttelet. A expansão das escolas de enfermagem no Brasil na primeira metade do século XX. Revista Eletrônica de Enfermagem, v. 1, n. 1, 1999. Disponível em: <www.fen.ufg.br/ revista>. Acesso em: 12 dez. 2001.

MENDES, Maria Manuela Rino. O ensino de graduação em enfermagem no Brasil, entre 1972 e 1994: mudança de paradigma curricular? Tese de Doutorado, Ribeirão Preto: Escola de Enfermagem, Universidade de São Paulo, 1996.

MISSIO, Lourdes. O entrelaçar dos fios na construção da identidade docente dos professores do curso de enfermagem da Uems. Tese de Doutorado, Campinas: Faculdade de Educação, Unicamp, 2007.

MOTT, Maria Lúcia. Revendo a história da enfermagem em São Paulo (1890-1920). Cadernos Pagu, v. 13, p. 327-355, 1999.

NIETSCHE, Elisabeta Albertina. As teorias da educação e o ensino da enfermagem no Brasil. In: SAUPE, Rosita (Org.). Educação em enfermagem. Florianópolis: UFSC, 1998. 
PANACHE, Graziela Giusti. A importância da formação pedagógica para o professor universitário: a experiência da Unicamp. Tese de Doutorado, Campinas: Faculdade de Educação, Unicamp, 2003.

PEREIRA, Paulo Fábio. Homens na enfermagem: atravessamentos de gênero na escolha, formação e exercício profissional. Dissertação de Mestrado, Porto Alegre: Faculdade de Enfermagem, UFRGS, 2008.

PIRES, Denise. Hegemonia médica na saúde e a enfermagem. São Paulo: Cortez, 1989.

RIZZOTTO, Maria Lúcia Frizon. (Re)vendo a origem da enfermagem profissional no Brasil: a Escola Anna Nery e o mito da vinculação com a saúde pública. Dissertação de Mestrado, Campinas: Faculdade de Educação, Unicamp, 1995.

RODRIGUES, Rosa Maria. Diretrizes curriculares para a graduação em enfermagem no Brasil: contexto, conteúdo e possibilidades para a formação. Tese de Doutorado. Campinas, SP: Faculdade de Educação, Unicamp, 2005.

SAUPE, Rosita (Org.). Educação em enfermagem: da realidade construída à possibilidade em construção. Florianópolis: Editora da UFSC, 1998.
SAVIANI, Demerval. História das ideias pedagógicas no Brasil. Campinas: Autores Associados, 2007.

SILVA, Tomaz Tadeu da. Documentos de identidade: uma introdução às teorias do currículo. 2. ed. Belo Horizonte: Autêntica, 2004.

SILVA, Maria Iracema Tabosa da; RUFFINO, Márcia Caron; DIAS, Mardônio Rique. Posicionamento de enfermeiras sobre ensino problematizador. Revista Latino-Americana de Enfermagem, v. 10, n. 2, p. 192 198, 2002.

SILVA, Rosiele Pinho Gonzaga; RODRIGUES, Rosa Maria. Mudança curricular: desafio de um curso de graduação em enfermagem. Revista Brasileira de Enfermagem, v. 61, n. 2, p. 233-238, 2008.

WALDOW, Vera Regina. Examinando o conhecimento na enfermagem. In: MEYER, Dagmar Estermann; WALDOW, Vera Regina; LOPES, Marta Júlia Marques (Orgs.). Marcas da diferença: saberes e fazeres da enfermagem contemporânea. Porto Alegre: Artes Médica, 1998.

Recebido em 03/11/2008

Aprovado em 09/06/2009 